\title{
Den otidsenliga böjningen: Föreställningar om den adjektiviska a- och e-böjningen 2002- 2014
}

\author{
Maria Bylin
}

\section{Inledning}

De senaste årens feministiska språkplanering och debatten av den har främst diskuterat pronomen, som hen och man/en, samt benämningar på yrkeskategorier och positioner som lärare, brandman, sjuksköterska, medan sexusböjningens - $a$ och - $e$ har bubblat lite utanför listan. ${ }^{1}$ Drabbar denna reform den enskilde individen eller den enskilda individen? Är det den unge eller den unga som ska välja gymnasieskola? Bäste Per Svensson eller Bästa Per Svensson? Och ska man överhuvudtaget kategorisera efter kön på det sätt som en sexusböjning gör?

Idéer om språkriktighet och genus möts i de språkideologiska föreställningarna om sexusböjningen, och den som söker råd i grammatikböcker och normerande handböcker förstår snart att användningsmönstren för adjektivböjningens - $a$ och -e är komplicerade: 'Då variationen mellan adjektivens $a$ - och $e$-former är så pass brokig och beroende av fler faktorer än kön är det svårt att ge något entydigt råd för den som vill använda ett jämställt språk" skriver Milles (2008:58). Det är ett påstående som denna artikel vill understryka och utveckla med stöd av en undersökning av de mejlfrågor som ställts till Språkrådet om - $a$ och $-e$, vilken ger en bild av normvariationen. Därefter diskuteras böjningen i förhållande till ett av de möjliga målen för feministisk språkplanering: "to create a language in which the sexes are treated in an equal and symmetrical manner" (Pauwels 1998:97). Syftet är alltså att redovisa de skilda analyser av - $a$ och - $e$ som kan göras, och diskutera vilka lösningar som kan härledas därur, samt olika sätt att förstå och definiera "ett språk i vilket könen behandlas lika och symmetriskt"

\section{Snabba fakta om den adjektiviska a- och e-böjningen}

Normerande litteratur som Hultman (2003:88-89), Språkriktighetsboken (2005:88-96) och Svenska skrivregler (2008:101) ger följande riktlinjer för böjningen. Om kvinnor bör - $a$ användas som i (1), utom vid vissa fasta tjänstebeteckningar, då - e rekommenderas, som (2):

(1) vår nya medarbetare Elina Jansson

(2) förste arkivarie Elina Jansson

\footnotetext{
${ }^{1}$ Denna forskning har gjorts möjlig genom bidrag från Erik Wellanders fond samt Anna Ahlström och Ellen Terserus stiftelse. Tack till Olle Josephson och Ola Karlsson för läsning och kommentarer.
} 
För manliga referenter rekommenderas i första hand s.k. maskulin-e, särskilt i formellare stilar, samtidigt som - $a$ också beskrivs som korrekt, men associerat till vardagligare stillägen. Följande varianter beskrivs alltså båda som normenliga:

(3) vår nye medarbetare Dylan Jansson

(4) vår nya medarbetare Dylan Jansson

I Bylin 2016a, 2016b undersöks det faktiska bruket av $-e$ och - $a$ för kvinnor och män, och det visar sig att det finns viss variation även för kvinnliga referenter, främst då de beskrivs som yrkespersoner eller innehavare av maktpositioner:

(5) Nye ordföranden Else-Marie Svensson

(6) VBK:s nye lagledare Frida Dahlgren

Att det främst är i dessa sammanhang som kvinnor får - $e$ framhålls också av den mer beskrivande Svenska Akademiens grammatik (1999:2:228-229), och som framgick ovan var det i "vissa fasta tjänstebeteckningar" som den normerande Svenska skrivregler rekommenderade $-e$ för kvinnor. Men även för män samvarierar offentliga roller och yrkesverksamhet med $-e$, på så sätt att även manliga referenter oftare får - $e$ i sammanhang där de omtalas som offentliga personer eller yrkesutövare än där de omtalas som privatpersoner (Bylin 2016b). Detta kan kopplas till det faktum att arbetslivet historiskt sett varit de manliga referenternas arena, så att maskulin-e kommit att associeras med yrkeslivet och formella texter, och utifrån den aspekten kan - $e$ beskrivas som något av ett tjänste- $e$ i kontrast till ett privat- $a$.

För generiska nominalfraser, som i och med att de är generiska, ska passa in på alla som täcks av nominalfrasens beskrivning oavsett kön, uppges att bruket varierar, samtidigt som adjektivets funktion som attributivt styr mot $-a$ (7) och självständig funktion styr mot $-e$ (7).

(7) Den nya medarbetaren ska hela tiden ha någon att rådfråga om något är oklart.

(8) Den nye ska hela tiden ha någon att rådfråga om något är oklart.

För att ytterligare komplicera mönstret används $-e$ då och då som ett animathets-e (SAG 1999:2:229, Bylin 2016b), dvs. om levande varelser som tillskrivs vilja och kontroll: hästar och hundar, företag, lag och andra kollektiver. Även män och kvinnor är förstås animater, så om man inkluderar dem kan man säga att animathet är det mest grundläggande villkoret för att använda $-e$.

Man kan alltså synkront uppfatta skillnaden mellan - $e$ och $-a$ på olika sätt i skilda sammanhang, som:

- maskulinum:femininum

- maskulinum:icke-maskulinum

- animathet:inanimathet

- offentligt:privat.

Ingen av dessa distinktioner täcker var för sig vare sig bruket eller det semantiska innehållet $\mathrm{i}$ $-e$ och $-a$, men alla är relevanta i olika sammanhang (jfr Bylin 2016b). 
Man antar ofta att denna variation är ett led i en förändring av sexusböjningen, men det finns inget som tyder på att det har förändrats särskilt mycket det senaste århundradet. Går man ytterligare några hundra år tillbaka i tiden har systemet dock sett annorlunda ut, och beroende på hur långt tillbaka man går kan man dock göra olika typer av beskrivningar. Man kan beskriva - $e$ som en historiskt sett manlig form eftersom den härstammar från en maskulin nominativändelse $\mathrm{i}$ det fornsvenska kasussystemet. Men även - $a$ skulle då kunna beskrivas som en manlig form, eftersom den bl.a. härstammar från en oblik maskulinändelse $-a$ (Wessén 1965). Men man skulle också kunna använda språkhistoriska argument för att beskriva - $a$ som en femininform i opposition till $-e$, t.ex. genom att åberopa den historiska tendensen att associera - $e$ till män och $-a$ till kvinnor generellt: pojkelflicka, gubbe/gumma, Tore/Tora (Tegnér 1886, Ståhle 1979). Möjligheterna att hämta olika argument ur språkhistorien är därmed på intet sätt uttömda, för användningen av - $a$ och - $e$ har inte följt något enkelt och konsekvent system, utan variationen har funnits i många hundra år, vilket framgår av bl.a. Tegnér 1886, Larsson 2004 och Santesson 1989. Sammanfattningsvis kan man alltså säga att böjningen är - och länge har varit - ett synnerligen mångfacetterat variationstillstånd. Därför kan det beskrivas på flera olika sätt, beroende på vilka betydelseaspekter som sammanhanget aktualiserar, och på vad man vill diskutera.

\section{Språknormer i variation}

Om bruket av - $a$ och - $e$ är komplext, så är föreställningarna om böjningen och tolkningen av dess former knappast mindre varierande. Här beskrivs sådana uppfattningar utifrån ett material bestående av frågor som ställts till Språkrådets rådgivning. Frågorna om $-a$ och $-e$ har alltså ställts spontant, och eftersom man bara frågar Språkrådet vid osäkerhet eller oenighet om språknormer ger materialet en bra bild av just normkonflikter. Men av samma skäl kan de inte ses som representativa för det svenska språksamhället i stort. Ytterligare ett skäl till att inte överskatta representativiteten i materialet är också att de flesta som ställer frågor till Språkrådet har språket som sitt yrkesredskap. De är redaktörer, skrivande handläggare, översättare, journalister och språkkonsulter, men även allmänheten kan ställa språkfrågor och gör det ibland också. Det är alltså inte några genomsnittliga språkbrukares föreställningar som utläses av detta material, utan frågor och kommentarer från personer som antingen har språket som yrke eller är tillräckligt språkintresserade för att kontakta Språkrådet på sin fritid.

I augusti 2014 innehöll Språkrådets arkiv över besvarade e-postfrågor strax under 50000 mejl, daterade från och med maj 2002 fram till augusti 2014, och som brev till myndighet är de offentliga handlingar. För att få ett mer förutsättningslöst grepp om vad frågorna handlar om gjorde jag först ett representativt urval på så sätt att jag gick igenom alla mejl under två slumpmässigt valda månader per år (jan-feb under 2014, mars-april 2013, maj-juni under 2012 osv.) och excerperade alla frågor som rörde adjektiviska ord på $-a$ och $-e$. Det resulterade i 31 mejl, vilket innebär att Språkrådet i genomsnitt har besvarat något mindre än en epostfråga om detta i månaden. Därefter gjordes sökningar på ord som ofta diskuterats i dessa sammanhang, som argal-e snickaren, förstelärare, bästal-e, och slutligen på maskulinum och femininum samt kvinna/man och kvinnlig/manlig. Resultatet av sökningarna blev totalt 192 frågor om $-a$ och $-e$, som utgör den empiriska grunden för analysen av tolkningar och föreställningar. 
För att skapa överblick har jag grovt kategoriserat de utgångspunkter som gått att utläsa $\mathrm{i}$ de 192 mejlfrågorna, och då funnit att:

- 25 frågeställare undrar om man bör böja efter kön, dvs. om det är rätt eller fel, bra eller dåligt med sexusböjning.

- 19 vill få Språkrådet att bekräfta att - $a$ är fel vid manlig referent, medan 21 vill få bekräftat att det är korrekt. Den typiska frågan utgår från en konflikt om en nominalfras, i vilken skribenten använt $-a$ för en manlig individ.

- 4 vill få Språkrådet att bekräfta att -e är fel för kvinnlig referent, medan 16 undrar om det ska vara $-a$ eller $-e$ i en specifik nominalfras som betecknar en kvinna.

- 19 vill få bekräftat att $-a$ är könsneutralt i en generisk eller anonymiserande nominalfras, medan 2 vill påtala att det inte är det.

- 8 utgår från att - $e$ är den könsneutrala formen i generisk eller anonymiserande nominalfras, medan 28 vill få bekräftat att det inte är det.

- 38 undrar vilken form de ska välja i en generisk eller anonymiserande nominalfras för att texten ska bli könsneutral. ${ }^{2}$

Ur materialet framträder alltså ett antal normkonflikter, som rör morfemens betydelser och kodandet av kön. Samtliga 192 frågeställare aktualiserar på ett eller annat sätt kön i frågan, medan andra faktorer som spelar roll för variationsmönstret, som genre och attributivitet eller självständighet, nämns av ytterst få. Med andra ord framstår referentens kön som den $a$ - och $e$-faktor som syns på radarn, medan övriga faktorer går under radarn. Närmare läsningar av frågorna uppdagar också en mängd sätt att tolka och förhålla sig till variationen utifrån olika sätt att se på språk och genusrelationer.

Även om alla är eniga om att $-a$ och - $e$ har med kön att göra, så råder det alltså delade meningar om huruvida man ska böja efter kön, och i så fall när - $a$ kan användas för en man eller - $e$ för en kvinna, liksom om vilken form som ska anses kunna representera båda könen i anonymiserande eller generiska funktioner. När denna oenighet kommer i dagen leder det också till osäkerhet om normen. Många presenterar en klar bild av vad de har lärt sig eller hur de anser att det ska vara, men ger sedan uttryck för de tvivel som uppstått när deras val av ändelse ifrågasatts av någon annan, eller när de iakttagit andras bruk av - $e$ och $-a$. Hur osäkerheten kan uppstå i mötet mellan olika normer får detta korta diskussionsreferat belysa:

Hej!

På mitt jobb dök frasen "den nya chefen" upp. Någon menade då att eftersom chefen är en man borde det heta "den_nye_chefen", av samma anledning som man säger den lilla flickan och den lille pojken. En tredje påstod då att ordet "nye" inte finns över huvud taget. Vilket är rätt? (15 juli 2008)

Mejlen avslutas ofta med kommentarer av typen:

\footnotetext{
${ }^{2}$ Om man lägger ihop dessa siffror får man inte 192, vilket beror på att vissa frågeställare gett uttryck för mer än en ståndpunkt, medan andra inte alls gått att placera in i dessa kategorier och då helt utelämnats ur denna grova kategorisering.
} 
[Vi] är emellertid i minoritet när det gäller denna fråga. Varför är vi det? Har vi fel? (13 sep 2007)

Så även om grunduppfattningen att detta med - $a$ och - $e$ är könskodning står stabil, så har de som ställer frågor påtagligt skilda uppfattningar om ifall och i så fall hur referentens kön ska kodas.

\section{Böjningen från förr i tiden}

En av de vanligaste utgångspunkterna i mejlen är att variationen beror på en förändringsprocess, vilket i en eller annan form antyds i 35 frågor. Förändringen antas alltid gå i den riktningen att man inte längre böjer efter kön, vilket användningen av fortfarande och bara vi äldre i dessa citat får exemplifiera.

Om jag tilltalar en kund per brev, gäller då fortfarande "bästa" för kvinnor och "bäste" för män, eller är detta föråldrat ... (30 maj 2011)

Skriver man fortfarande "Bäste Alexander" och "Bästa Anna", dvs könsspecifik ändelse (28 jan 2014)

Är det bara vi äldre som bemödar oss om att skriva som vi lärde i skolan, t. ex. den "nye kungen" respektive "den nya drottningen"? (22 juni 2014)

Sexusböjningen beskrivs som en generationsfråga, och frågeställarna tolkar ofta variationen som ett tecken på att systemet håller på att luckras upp. Som skäl till den hypotesen anförs ofta det faktum att - $a$ används om män, vilket av många frågeställare uppfattas som direkt felaktigt. En av de frågeställare som också kommenterar språkbrukets påverkan på korrektheten, återges här:

Jag har märkt att man i media oftast använder en feminin böjning av adjektiv:

"Den tjugotvååriga mannen"

"Den amerikanska presidenten Obama"

"Arga snickaren"

"Den pålästa och kluriga Göran Persson"

För mig är detta väldigt dålig svenska, men eftersom språkbruket fungerar så att om tillräckligt många gör fel så blir det så småningom rätt. Frågan blir därför om det numera är acceptabelt att inte korrekt böja adjektiven? (17 dec 2012)

Frågeställaren är på intet sätt ensam om att anta att - $a$ är en ren femininändelse, utan har sällskap av 18 andra. Att denna uppfattning är så pass vanlig är intressant, med tanke på att normerande litteratur från Wellander (1939:196-197, 1970:196-197, 1973:102) till Svenska skrivregler (1991:44, 2000:72, 2008: 100) beskriver - $a$ för manlig referent som en frekvent och korrekt, om än stilmässigt informellare, variant till -e. Att uttryck som idag, nu och numera används så ofta i frågorna ger vid handen att skribenterna tror att - $a$ inte alltid har an- 
vänts för män, utan att det kommit först på senare tid. Den uppfattningen verkar också vara den vanligaste grunden till föreställningen att systemet är i upplösning.

Men även användningen av -e leder ibland till liknande tankar. Tre frågeställare antyder att systemet luckras upp av att - $e$ ibland används för kvinnor. Innan man kontaktar Språkrådet har man ofta konsulterat någon normkälla, och att SAOL inte tar upp $e$-former tas enstaka gånger till intäkt för att $e$-formerna inte är riktigt lika korrekta som $a$-formerna: "Hittar inte $\mathrm{e}$ som ändelse på ny i SAOL nämligen", skriver en korrekturläsare som undrar om det inte är dags att sluta med $e$-böjning (27 maj 2014).

Föreställningen om att sexusböjningen befinner sig i en förändringsfas och är på väg bort är alltså påtagligt frekvent. Den tänkta utgångspunkten för denna förändring är ett system där nominalfraser som refererade till män alltid fick - $e$ och de som refererade till kvinnor alltid $a$, dvs. frågeställarna utgår från en enhetlighet som aldrig har funnits. Om denna tänkta enhetlighet i sexusböjningen skulle ha varit bra eller dålig tycker de olika om, men oavsett om de har en positiv eller negativ syn på konsekvent sexusböjning verkar de uppfatta den som något från "förr i tiden".

\section{Språkformerna och genusnormerna}

Könsneutralitet har varit viktigt i det offentliga språket under det senaste decenniet, vilket bland annat visar sig i att 38 av mejlen efterfrågar en könsneutral form. Flera frågor anknyter explicit till genusmedvetenhet och strävan efter jämställdhet och/eller könsneutralitet:

Vi har funderingar nu när vi ska ha ett jämställt språk. Ur ett genusperspektiv ska e bytas ut mot a i ord som lille, store och bäste att bli lilla och stora. (17 okt 2011)

Läser korrektur och några yngre personer undrade om man verkligen skriver nye när det är en man i dessa hentider. (27 maj 2014)

Är det självklart att använda "den anställde" trots att både kvinnor och män inkluderas? Jag anar en smygmaskulinisering i språket och jämför med varför ordet "hen" har introducerats. (14 maj 2012)

Några verkar uppfatta sexusböjning som ett avsteg från principen om likabehandling av könen, som nedanstående frågeställare.

Ska jag ändra ändelsen i adjektiv beroende på om jag skriver om en man eller kvinna? "Den demente pappan" vs. "Den dementa mamman"? Det heter ju "dementa" i alla andra avseenden och borde väl så göra oberoende av kön också, eller har jag helt fel? (5 juli 2013)

Heter det "den jämtländske polisen Ingrid Kvarnberg" eller "den jämtländska polisen Ingrid Kvarnberg" Ska man blanda in det faktum att Ingrid är en kvinna i det där? (29 april 2013)

Men hur man ska lyckas förhålla sig könsneutral med en sexusböjning i variation är långt ifrån givet. Som framgick ovan är det mer än dubbelt så vanligt att man utgår från att $-a$ är könsneutralt som att $-e$ är det (19 respektive 8 frågor), även i självständig användning. Det är också mycket vanligare att - $e$ ifrågasätts som könsneutral form än att $-a$ gör det (28 respektive 2 frågor). Doktoranden nedan verkar t.ex. ha använt $-e$ som könsneutral form i självständig användning på ren ryggradsreflex, och sedan kommit att ifrågasätta sitt eget val: 
Jag skriver en avhandling om ungdomar i institutionsvård och använder ganska ofta uttrycket "den unge". Är medveten om att det är ovanligt men har förstått att det iaf inte är felaktigt. Eftersom materialet är kvantitativt och jag inte talar om specifika individer har jag tyckt att detta ordval passar bäst. Min fråga gäller i vilken utsträckning detta begrepp är könsneutralt? När jag använder det talar jag om både pojkar och flickor och jag har för mig att jag hört att "den unga" passar bättre när man talar om båda könen. Stämmer det? (21 aug 2012)

Frågan speglar förstås en osäkerhet kring normerna för könsneutralitet, men också en medvetenhet om att de egna normerna inte delas av alla. Om bakgrunden till att $-e$ och $-a$ nu ofta uppfattas som könade i generiska användningar kan jag dock bara spekulera, för även om frågeställarna har reflekterat över varför de uppfattar - $e$ eller - $a$ som könade i generiska sammanhang, så är det inget de explicitgör i frågorna.

Den slutsats jag drar av materialet är i likhet med Milles (2008:58) att det idag inte finns någon form som man med säkerhet kan beskriva som könsneutral $\mathrm{i}$ alla lägen, vare sig $\mathrm{i}$ generiska eller anonyma. Det ogynnsamma läget är det också två frågeställare som utgår från. De är båda handläggare som skriver med ambitionen att uttrycka sig könsneutralt, och den lösning båda föreslår för att slippa markera kön är ett alexanderhugg, dvs. ingen ändelse alls, vilket kanske kan uppfattas som adverbiellt när huvudordet utgörs av ett particip, som i det följande exemplet.

I rekryteringssituationer anställer vi den bäste sökande utan hänsyn till kön, ålder, ras, nationalitet, religion, handikapp eller sexuell läggning. Kan man skriva "den bäst sökande" för att vara neutral beträffande kön. (4 jan 2005)

Formerna - $a$ och - $e$ framstår här som ett problem, vilket bäst löses genom språklig kreativitet.

Samtidigt är det långt ifrån alla frågeställare som vill undvika könskodning. Flera uppfattar det som positivt och reagerar när det uteblir, som frågeställaren nedan.

Jag tjatar ihjäl kollegor om att de måste skilja på han och hon. Jag säger att "Den svenska ambassadören i Kenya" måste vara en kvinna. Lik f-b visar det sig att "hon" heter Gunnar Karlsson. Typ!

Undrar alltså om det är så att man i dag helt har lämnat denna lilla finess, att med ett -a eller ett -e visa vilket kön det är på vederbörande? (9 dec 2009)

Eftersom personen engagerar sig i sina kollegors adjektivböjning, och beskriver sexusböjningen som "en finess", får man anta att skribenten uppfattar böjningen som positiv - även om den också förskriver sig till uppfattningen att detta är en omodern böjning genom att undra om "man idag helt har lämnat" den.

Det saknas inte heller män som påtalar att de vill bli tilltalade eller omtalade med $-e$ :

Jag vill t ex inte bli beskriven som: "den gaggiga, gamla, 71-åriga stöten.” Nej "den gaggige, gamle, 71-årige stöten." skall det vara enl min mening. (13 april 2014)

Dessa män uppfattar uppenbarligen $-a$ som feminin- $a$, och reagerar då det används till dem eller om dem. Av mejlen framgår också att det finns kvinnor som inte alls vill bli tilltalade med $-e$ :

Jag undrar vad som är korrekt. 
Inleder man ett brev med "Bästa kund" eller "Bäste kund"?

En kund blev förargad när den läste "Bäste kund" på sin faktura och ansåg att det enbart vänder sig till män.

Hur är det egentligen? (23 november 2013)

Sammanfattningsvis kan man säga att undersökningen visar på en oenighet om vad - $a$ respektive - $e$ signalerar i olika sammanhang, liksom på en osäkerhet om hur man ska uttrycka sig könsneutralt. Det varierar i vilka kontexter som osäkerhet kring - $e$ och $-a$ uppstår, men för de flesta är det vid anonym eller generisk referens som frågan aktualiseras. Utbredd enighet råder om att sexusböjning är något som håller på att försvinna (vilket att döma av resultaten i Bylin 2016b inte alls är sant), även om det varierar om man ser det som en positiv eller negativ utveckling. Enstaka frågeställare verkar nämligen se sexusböjningen som ett avsteg från likabehandlingsprincipen, medan andra tvärtom uppfattar det som lämpligt och positivt att signalera referentens kön.

Efter att ha etablerat att användningsmönstren är mångskiftande och normföreställningarna likaså, vill jag nu diskutera hur en feministisk språkplanering av detta variationstillstånd skulle kunna te sig, för precis som vid alla andra språkliga variationstillstånd kan föreställningar om rätt och fel, bra och dåligt, knytas till variantformerna. Språkliga normer är aldrig ideologineutrala, och därav följer att ideologineutral språkvård eller språkplanering knappast är tänkbar (jfr Cooper 1989:35, Vikør 1994:42). Men hur en ideologisk utgångspunkt knyts till en viss språkplaneringsrekommendation är långt ifrån självklart, vilket den nu följande diskussionen vill belysa.

\section{Hur skulle en feministisk språkplanering kunna se ut?}

Inom feministisk lingvistik har grammatik i vid mening ofta antagits reproducera sexistiska strukturer. "Grammar is politics by other means" skriver Donna Haraway, utan att närmare gå in på vad hon menar med grammar (Haraway 1991:3). Och ofta ska grammar i sådana uttalanden kanske snarare förstås som '(språklig) struktur' än 'grammatik', men några mer specifika delar av språkstrukturen som feministisk språkkritik ofta satt ljuset på är just grammatiskt och semantiskt genus, liksom olika former av manlig generiskhet (Cooper 1984, Pauwels 1989, Hornscheidt 2003, Wojahn 2015). Eftersom det är olika men besläktade saker, kommer jag först att diskutera sexusböjningen, som blir aktuell då man refererar till specifika individer, för att därefter diskutera generiska eller anonymiserande användningar.

Sexusböjning överhuvudtaget kan man förespråka utifrån en traditionellt konservativ idé om att det är viktigt att separera könen binärt, men också från en feministisk idé om könsspecificering som ett synliggörande av kvinnor. En normkritisk utgångspunkt brukar vara att människor själva ska få välja hur de vill bli benämnda, och de män som vill bli tilltalade med - $e$ och de kvinnor som vill tilltalas Bästa kund! skulle därmed kunna tas till intäkt för sexusböjningens moraliska giltighet.

Men sexusböjning kan man också invända mot utifrån en feministisk idé om att irrelevantgöra kön genom neutralisering, liksom utifrån en vilja att luckra upp den binära tvåkönsnormen. De två ambitionerna kan, men måste inte, kombineras. En feministiskt inriktad språkplanering kan vilja verka för ett tillstånd där distinktionen omtolkas från att primärt 
signalera maskulinum:femininum till någon annan innebörd av variationen, som till exempel offentligt:privat, så att kvinnor och individer med icke-binärt kön får - $e$ lika ofta som män i offentliga texter. Eller så kan den förespråka ett tillstånd där alla mänskliga individer alltid får samma form oavsett kön, varpå man kan välja att språkplanera antingen mot ett animathets-e gentemot inanimathets- $a$, eller i enlighet med den funktionella språkvårdsnormen mot ett - $a$ som allroundform för alla referenter och ökad enhetlighet. Den ideologiska bevekelsegrunden avgör helt enkelt inte ensam formfrågan.

Maskulina former har ofta en parallell användning som generiska, vilket kan ses som att kvinnor osynliggörs genom att inkluderas i manliga former (Pauwels 1998:41-43, Wojahn 2015:73-102). Pauwels menar att detta är sexistiskt och påpekar att feministisk språkplanering har störst chans att lyckas om många språkbrukare uppfattar en språklig form som sexistisk, förutsatt att de också uppfattar språklig sexism som ett problem (1998:66). Som framgick av undersökningen ovan är det uppenbart att det finns folk i Sverige som uppfattar adjektiviskt - $a$ och - $e$ som problematiskt i genushänseende, såväl i generiska som i specifika användningar, vilket gör det till en potentiell kandidat för feministisk språkplanering à la Pauwels. Men som Pauwels understryker har feministiska språkplanerare "very different views on what language is, how it operates, how meaning is created and how linguistic change occurs" (1998:95), och även om målet kan formuleras som "a language in which the sexes are treated in an equal and symmetrical manner" (Pauwels 1998:97), så är det inte självklart vilket tillstånd den skulle sträva mot, än mindre vilka lösningar som leder dit. Lösningen kan vara pragmatisk eller radikal, den kan vara orienterad mot jämställdhet mellan kvinnor och män, eller sträva mot en könsneutralitet som inkluderar även andra könsidentiteter.

Man kan t.ex. förespråka - $a$ som könsneutral form utifrån en feministisk idé om att den mer feminina formen bör bli den generiska, för att uppväga alla maskulina generiska uttryck i resten av språket. Det resonemanget bygger på en analys av - $a$ som i grunden feminint, vilket inte är den enda möjliga analysen. Hur man ser på - $a$ beror nämligen på vad man ser det $\mathrm{i}$ opposition till: maskulin-e, offentlighets-e eller animathets-e, liksom på om man väger in historiska förhållanden, och i så fall vilka. Den maskulina oblika kasusändelsen är, som framgick ovan, en av flera källor till dagens - $a$.

Man kan också förespråka - $e$ som könsneutral form, som då också skulle kunna användas om kvinnor, utifrån minst två ideologiska ståndpunkter som kan beskrivas som varandras motsatser. Å ena sidan från en feministisk idé om att - $e$ är en tjänste- och maktmarkör som inte bara manliga referenter borde förses med, å andra sidan från en direkt patriarkal idé om att maskulina former är normen som kvinnor får anpassa sig till.

Om man ser till målet så är det heller inte självklart på vilken språklig nivå det ska ligga. Som framgick av undersökningen ovan utgår de som ställer frågor till Språkrådet vanligtvis från att det svenska språksamhället behöver enas om en könsneutral form, som helst ska kodifieras och rekommenderas av Språkrådet. Två frågeställare tänker annorlunda och menar att ingen ändelse alls vore en tänkbar lösning. Och om man bara ser till det enskilda morfemets betydelse så krävs det att språksamhället enas om att ett av morfemen $-a$ eller $-e$ har könsneutral betydelse, eller att en ny, könsneutral ändelse (t.ex. - $\ddot{a}$ eller ett nollmorfem) lanseras och sprids. Men om man i stället för att fokusera på det enskilda morfemet tar det svenska språkbruket som utvärderingsnivå, så skulle man kunna argumentera för att språkbruket 
vore jämställt om - $e$ och - $a$ användes ungefär lika ofta i generiska användningar. Då blir snarare ett tillstånd med $50 \%-e$ och $50 \%-a$ målet, och i så fall skulle man kunna beskriva målet som nästintill uppnått, eftersom - $e$ och $-a$ verkar vara ungefär lika frekventa i generiska nominalfraser. ${ }^{3}$ Statistisk frekvens har visserligen den nackdelen att man inte som individ kan välja den för att signalera sin ideologiska grupptillhörighet, så som man kan göra med ett könsneutralt morfem. Men annars skulle man också kunna tänka sig att man i feministisk språkplanering aktualiserar det grammatiska systemet som helhet, och sätter målet att maskulinum och femininum ska ge upphov till lika många generiska morfem (pronomen, adjektivändelser etc.), eller - om man väljer en radikalt könsneutral inriktning - att alla ska nyskapas som könsneutrala. Det är alltså inte givet vad målet för en feministisk språkplanering av grammatiken skulle vara, eller när vi skulle bedöma den som jämställd respektive könsneutral.

Två slutsatser följer alltså av denna studie. Den första är att det idag inte finns någon helt könsneutral adjektivändelse för generiskt och anonymiserande bruk. Den andra är att det inte heller finns något ett-till-ett-förhållande mellan formval och ideologisk ståndpunkt när det gäller - $e$ och $-a$. Samma form kan förespråkas utifrån mycket skilda ideologiska ståndpunkter, och samma ideologiska ståndpunkt kan leda till olika formval.

\section{Referenser}

Bylin, Maria 2016a. Om den så kallade sexusböjningen: Tolkningen av adjektivböjningens - $a$ och -e. I: A. W Gustafsson, L. Holm, K. Lundin, H. Rahm och M. Tronnier (red.) Svenskans beskrivning 34: Förhandlingar vid Trettiofjärde sammankomsten Lund den 22-24 oktober 2014. Lund. S. 119-132.

Bylin, Maria 2016b. Adjektivböjningens $-a$ och $-e$. Ett seglivat variationstillstånd. I: Språk och stil NF 26. S. 69-100.

Cooper, Robert L. 1984. The avoidance of androcentric generics. International Journal of the Sociology of Language. 50. S. 5-20.

Cooper, Robert L. 1989. Language planning and social change. Cambridge: Cambridge University Press.

Haraway, Donna 1991. Simians, Cyborgs, and Women. The Reinvention of Nature. New York: Routledge.

Hornscheidt, Antje 2003. Linguistic and public attitudes towards Gender in Swedish. I: (red.) M. Hellinger \& H. Bussman Gender Across Languages: The Linguistic Representation of Women and Men. Vol.3.

Hultman, Tor G. 2003. Svenska Akademiens Språklära. Stockholm: Svenska Akademien.

Larsson, Ida 2004. Språk i förändring. Adjektivändelserna - a och -e från fornsvenska till nysvenska. (MISS 49) Göteborg: Göteborgs universitet.

Milles, Karin 2008. Jämställt språk. En handbok $i$ att skriva och tala jämställt. Stockholm: Norstedts akademiska förlag.

Pauwels, Anne 1998. Women changing language. London \& New York: Longman.

SAG = Teleman, Ulf Hellberg, Staffan \& Andersson, Erik 1999. Svenska Akademiens grammatik. 1-4. Stockholm: Svenska Akademien.

\footnotetext{
${ }^{3}$ Bylin 2016b redovisar $56 \%$ för $-e$ och $44 \%$ för $-a$ i generiska nominalfraser (attributiva och självständiga sammanslagna).
} 
Santesson, Lillemor 1986. Tryckt hos Salvius. En undersökning om språkvården på ett 1700talstryckeri med särskild hänsyn till ortografi och morfologi. (Lundastudier i nordisk språkvetenskap) Lund: Lund University Press.

Språkriktighetsboken 2005. Utarbetad av Svenska språknämnden. Stockholm: Nordstedts akademiska förlag.

Ståhle, Carl Ivar 1979. Svaga maskuliner i nysvenskan. Ett stycke svensk språk- och sparkvårdshistoria. I: Språknorm och språkform. En bok till Bertil Molde på 60-årsdagen den 16 september. Stockholm: Esselte studium. S. 203-235.

Svenska skrivregler 1991. Utg. av Svenska språknämnden. Stockholm: Almqvist \& Wiksell Förlag.

Svenska skrivregler 2000. Utg. av Svenska språknämnden. Stockholm: Liber.

Svenska skrivregler 2008. Utg. av Språkrådet. Stockholm: Liber.

Tegnér, Esaias 1886. Om genus i svenskan. (Svenska Akademiens handlingar 6) Stockholm: Kungl. Boktryckeriet P. A. Nordstedt \& söner.

Wellander, Erik 1939. Riktig svenska. Stockholm: P.A. Nordstedt \& Söner.

Wellander, Erik 1970. Riktig svenska. Stockholm: P.A. Nordstedt \& Söner.

Wellander, Erik 1973. Riktig svenska. Stockholm: Esselte Studium.

Wessén, Elias 1965. Svensk språkhistoria. I. Ljudlära och formlära. (Tredje upplagan) Stockholm.

Vikør, Lars S. 1994. Språkplanlegging. Prinsipp og praksis. Oslo: Novus forlag.

Wojahn, Daniel 2015. Språkaktivism Diskussioner om feministiska språkförändringar $i$ Sverige från 1960-talet till 2015. Uppsala: Institutionen för nordiska språk, Uppsala universitet. 